\title{
Gamma-aminobutyric acid (GABA) production in milk fermented by specific wild lactic acid bacteria strains isolated from artisanal Mexican cheeses
}

\author{
Alejandro Santos-Espinosa', Lilia María Beltrán-Barrientos', Ricardo Reyes-Díaz', Miguel Ángel Mazorra-Manzano ${ }^{1}$, \\ Adrián Hernández-Mendoza', Gustavo Adolfo González-Aguilar², Sonia Guadalupe Sáyago-Ayerdi, \\ Belinda Vallejo-Cordoba ${ }^{1}$ and Aarón Fernando González-Córdova ${ }^{1 *}$ (i)
}

\begin{abstract}
Purpose: The purpose of this study was to screen wild GABA-producing lactic acid bacteria (LAB) isolated from artisanal Mexican cheeses and to evaluate the fermentation conditions for the enhancement of the GABA yield in fermented milk.

Methods: A qualitative test was carried out to select the GABA-producing LAB and the GABA was quantified by reversed-phase high-performance liquid chromatography in fermented milk (FM). Two inoculum concentrations $\left(10^{7}\right.$ and $\left.10^{9} \mathrm{CFU} / \mathrm{mL}\right)$, two incubation temperatures $\left(30\right.$ and $\left.37^{\circ} \mathrm{C}\right)$, three glutamate concentrations $(1,3$, and $5 \mathrm{~g} / \mathrm{L})$, and three pyridoxal $5^{\prime}$-phosphate (PLP) concentrations $(0,100$, and $200 \mu \mathrm{M})$ were assessed to establish suitable conditions to enhance the GABA yield in FM.
\end{abstract}

Results: Results showed that, from a total of $94 \mathrm{LAB}$ strains, fermented milk with two Lactococcus lactis strains (L-571 or L572) presented the highest GABA production. However, $37^{\circ} \mathrm{C}$ of incubation and $10^{9} \mathrm{CFU} / \mathrm{mL}$ and $3 \mathrm{~g} / \mathrm{L}$ of glutamate significantly led the highest GABA yield in FM with L-571. Further studies are needed to establish the optimum conditions for producing GABA by this strain, and in vivo studies may reveal its potential use as GABA-producing culture.

Conclusion: These results highlight the importance of wild $L A B$ strains in order to generate new alternatives and opportunities in the development of functional foods containing GABA.

Keywords: GABA, Lactic acid bacteria, Artisanal Mexican cheeses, Fermented milk

\section{Introduction}

In recent years, interest in the production of GABA has increased because of its multiple beneficial effects. GABA may act as an inhibitory neurotransmitter and also have antianxiety, antidepressant, and antihypertensive properties. Additionally, the consumption of GABA may inhibit the proliferation of cancer cells, be used in the treatment of Alzheimer's and Parkinson's disease, regulate thyroid

\footnotetext{
* Correspondence: aaronglz@ciad.mx

'Laboratorio de Química y Biotecnología de Productos Lácteos, Centro de Investigación en Alimentación y Desarrollo, A. C. (CIAD, A.C.), Carretera Gustavo Enrique Astiazarán Rosas \# 46, Colonia La Victoria, 83304 Hermosillo, Sonora, Mexico

Full list of author information is available at the end of the article
}

hormone levels, and improve the immune system (Diana et al. 2014a). Recent research has focused on natural ways of producing GABA as a bioactive compound for use in the pharmaceutics and food industries. In particular, fermentation by LAB may produce GABA in its most natural and suitable form (Xu et al. 2017).

LAB produces GABA during fermentation as a defense mechanism to maintain viability under acidic conditions. The glutamate decarboxylase (GAD) of LAB uses pyridoxal 5'-phosphate (PLP) as a cofactor; when activated, it catalyzes the $\alpha$-decarboxylation of glutamic acid or its salts present in the medium (Shi and Li 2011; Xu et al. 2017). The GABA-producing ability of different LAB strains may vary and depends on different fermentation 
parameters or additives, including $\mathrm{pH}$, temperature, cultivation time, PLP addition, and medium composition (Song and Yu 2017).

Various GABA-producing bacteria have been isolated from tea leaves, fermented fish, kimchi, and yogurt (Komatsuzaki et al. 2005; Jeng et al. 2007; Lu et al. 2008). Further studies have focused on isolating GABA from new sources or on screening new GABAproducing LAB with a high biosynthesis capacity performed by wild strains isolated from nature (Franciosi et al. 2015). Actually, recent investigations reported a high concentration of GABA in "Crema de Chiapas cheese," a Mexican artisanal cheese, suggesting the presence of LAB with the capability to synthesize GABA (Gonzalez-Gonzalez et al. 2019). In this sense, artisanal Mexican dairy products possess an undiscovered variety of LAB that may be a rich source of strains with considerable GABA production capacity. Therefore, to provide a basis for the potential development of new healthpromoting fermented dairy products, the aim of the present study was to screen wild GABA-producing LAB isolated from artisanal Mexican cheeses and to evaluate the fermentation conditions for the enhancement of the GABA yield in fermented milk (FM).

\section{Materials and methods}

\section{Strains and growth conditions}

A total of 94 LAB strains of different genera (Lactobacillus spp., Lactococcus spp., and Streptococcus spp.) were assessed. All the strain cultures used (stored at $-80{ }^{\circ} \mathrm{C}$ in glycerol 10\%) are part of the Dairy Laboratory collection in the Centro de Investigación en Alimentación y Desarrollo, A.C. (CIAD, Hermosillo, Sonora, Mexico). These strains were isolated from the processes of three artisanal Mexican cheeses (Lactobacillus spp. from Cocido cheese (Heredia 2011), Lactococcus spp. from Chihuahua cheese (Gutierrez 2008), and Streptococcus spp. from Fresco cheese (Serrano 2012)). The Lactococcus strains were reactivated by inoculating $1 \%(\mathrm{v} / \mathrm{v})$ of each culture in sterile M17 broth (BD Difco; Spark, MD, USA) supplemented at $5 \%(\mathrm{v} / \mathrm{v})$ with a sterile $10 \%$ lactose solution (BD Difco, Spark, MD, USA). The Lactobacillus and Streptococcus strains were reactivated by inoculating $1 \%(\mathrm{v} / \mathrm{v})$ with MRS broth (BD Difco; Spark, MD, USA). The strains were then incubated for $24 \mathrm{~h}$ at $30{ }^{\circ} \mathrm{C}$ and $37{ }^{\circ} \mathrm{C}$, respectively. This procedure was repeated twice to obtain fresh cultures with a final concentration of $10^{7} \mathrm{CFU} / \mathrm{mL}$ (RodríguezFigueroa et al. 2010).

\section{Qualitative test for the detection of GABA-producing strains}

To select strains that potentially produce GABA, a GAD colorimetric assay was carried out. For this purpose, 5
$\mathrm{mL}$ of each fresh culture was centrifuged (Sorvall ST 16 centrifuge, Thermo Scientific, Chelmsford, MA, USA) at $4696 \times g$ for $20 \mathrm{~min}$ at $25{ }^{\circ} \mathrm{C}$. The pellet was recovered and resuspended in $5 \mathrm{~mL}$ of a $0.9 \% \mathrm{NaCl}$ solution. Afterwards, the suspension was centrifuged again under the same conditions and the pellet was homogenized with $0.5 \mathrm{~mL}$ of a GAD solution $(1 \mathrm{~g}$ of glutamic acid, $0.3 \mathrm{~mL}$ of Triton X-100, $90 \mathrm{~g}$ of $\mathrm{NaCl}$, and $0.05 \mathrm{~g}$ of bromocresol green in $1 \mathrm{~L}$ of distilled water, adjusted to $\mathrm{pH} 4$ ), followed by an incubation at $37^{\circ} \mathrm{C}$ during $4 \mathrm{~h}$ under anaerobic conditions (Cotter et al. 2001). After this time, the colorimetric reaction was visually observed and all the strains that turned the color green to blue were selected as it was shown by the Lactobacillus brevis (NBRC 12005) strain used as a positive control (Lacroix et al. 2013).

\section{Production of $\mathrm{FM}$}

The selected GABA-producing strains were evaluated for their ability to produce GABA in FM. A starter culture was prepared from each strain by adding fresh culture $(3 \%, \mathrm{v} / \mathrm{v})$ into $5 \mathrm{~mL}$ of $10 \%(\mathrm{p} / \mathrm{v})$ sterile $\left(110{ }^{\circ} \mathrm{C}, 10\right.$ min) reconstituted commercial semi-skimmed milk (ALPURA $^{\circ}$ ), which its composition was of $46.9 \%$ of total carbohydrates, $29.5 \%$ of protein, and $13 \%$ of fat. The inoculated milk was incubated for $12 \mathrm{~h}$ at $30{ }^{\circ} \mathrm{C}$ (Lactococcus spp.) or $37^{\circ} \mathrm{C}$ (Lactobacillus spp.). After the incubation period, a $3 \%(\mathrm{v} / \mathrm{v})$ aliquot of this starter culture was taken and added into $10 \mathrm{~mL}$ of $10 \%(\mathrm{w} / \mathrm{v})$ sterile reconstituted semi-skimmed milk and finally incubated for $48 \mathrm{~h}$ at $30{ }^{\circ} \mathrm{C}$ or $37^{\circ} \mathrm{C}$. pH was determined at the time of milk inoculation $(0 \mathrm{~h})$ and at $48 \mathrm{~h}$ of fermentation.

\section{Preparation of aqueous extracts}

After the incubation process, the fermentation was stopped by applying heat treatment $\left(75^{\circ} \mathrm{C}, 15 \mathrm{~min}\right)$ followed by a quick cooling in order to inactivate LAB. Samples of $10 \mathrm{~mL}$ were collected from each FM and centrifuged (Thermo Scientific, Chelmsford, MA, USA) at $4696 \times g$ for $1 \mathrm{~h}$ at $4{ }^{\circ} \mathrm{C}$, and the supernatants were recovered and storage at $-80{ }^{\circ} \mathrm{C}$ for further analyses (Beltrán-Barrientos et al. 2018b).

\section{Quantification of GABA in FM}

The GABA production in aqueous extracts from FM was quantified by reversed-phase high-performance liquid chromatography in a Series 1260 Infinity HPLC system (Agilent Technology, Waldbronn, Germany). Aliquots of $2 \mathrm{~mL}$ were centrifuged (Eppendorf, Hauppauge, $\mathrm{NY}, \mathrm{USA}$ ) at $12000 \times \mathrm{g}$ for $10 \mathrm{~min}$ at room temperature to remove solids and bacterial cells and were then ultrafiltered through membranes with a pore size of $<3 \mathrm{kDa}$ (Pall Life Sciences, Port Washington, NY, USA) (Wu and Shah 2016). Afterwards, a derivatization of the 
extracts was made in a precolumn following the methodology of the 6-aminoquinolyl-n-hydroxy succinimidyl carbamate commercial kit AccQ-Tag (Waters Corporation, Ciudad de México, México).

Chromatographic separation was performed using an AccQ-Tag C18 column $(1.7 \mu \mathrm{m}, 2.1 \times 100 \mathrm{~mm})$ maintained at a constant temperature $\left(37^{\circ} \mathrm{C}\right)$. Mobile phase A consisted of an AccQ-Tag ultra-eluent A, and phase B consisted of AccQ-Tag ultra-eluent B. Finally, phase C consisted of an eluent of Milli- $Q$ water. The gradient separation times were set as follows: (A:B:C), $0 \mathrm{~min}$, (100:0:0), $0.5 \min (100: 0: 0), 18 \min (95: 5: 0), 19 \min (91$ : 9:0), $29.5 \mathrm{~min}$ (83:17:0), $38 \mathrm{~min}(0: 60: 40)$, and $41 \mathrm{~min}$ (100:0:0). Detection was performed by UV absorbance at 254 $\mathrm{nm}$ to quantify GABA (Diana et al. 2014b).

\section{Strategies to enhance the GABA production}

The LAB strains that showed the highest GABA production were selected to assess the conditions to enhance the production of GABA in FM. The selected LAB strains were subjected to evaluate the conditions of fermentation in milk (enriched with $1 \mathrm{~g} / \mathrm{L}$ of glutamate): two concentrations of inoculum $\left(10^{7}\right.$ and $\left.10^{9} \mathrm{CFU} / \mathrm{mL}\right)$ and two different incubation temperatures $\left(30\right.$ or $\left.37^{\circ} \mathrm{C}\right)$. After selecting those fermentation conditions with the highest GABA production, three concentrations of glutamate $(1,3$, and $5 \mathrm{~g} / \mathrm{L})$ and three concentrations of PLP $(0,100$, and $200 \mu \mathrm{M})$ were assessed one factor at a time, to establish the suitable conditions to enhance the GABA production for each strain. The milk was enriched with these additives before the fermentation process. It is important to mention that preliminary results (data not shown) revealed that the selected conditions (glutamate, PLP concentrations, temperatures, and inoculum concentrations) did not affect the survival of lactic acid bacteria. The quantification of GABA was performed as described in the previous section.

\section{Statistical analysis}

A one-way analysis of variance (ANOVA), through a completely randomized design, was used to analyze data corresponding to $\mathrm{pH}$ and GABA concentration in order to select the best strains, glutamate concentration, and PLP concentration. Additionally, a general linear model (GLM) ANOVA was applied to select the fermentation conditions (inoculum concentration and incubation temperature). All these analyses were applied to determine which conditions may exert a greater effect on GABA production in FM. All the experiments were carried out in triplicate. When differences $(p \leq 0.05)$ among means were found, the Tukey-Kramer test was applied and all the analyses were performed by using the NCSS 2007 statistical software (Hintze 2006). The figures were made using the program GraphPad Prism version 5.0.

\section{Results and discussion}

Qualitative colorimetric assay of GABA-producing strains The colorimetric assay allowed us to analyze qualitatively the strains that may potentially synthesize GABA in the culture medium or food matrix (Yu et al. 2011). The results indicated that, from the 54 Lactobacillus spp., 16 strains (29.6\%) and, from 8 Lactococcus spp., 3 strains (37.5\%) were able to produce GABA; however, Streptococcus spp. strains did not show the capacity to synthesize GABA (Table 1). Since this colorimetric assay uses the green bromocresol compound, which is highly sensitive to proton consumption and referring to the color difference, qualitatively indicates which strains display the production of GABA. This behavior of LAB is directly related to the degree of activity of GAD, since this enzyme is responsible to convert glutamate to GABA. Therefore, the 19 positive GABA-producing strains (20.2\% from 94 strains assessed) were closely related to the presence and activation of the GAD enzyme (Komatsuzaki et al. 2008).

The production of GABA by fermenting microorganisms is a defense mechanism in response to different types of stress, mainly exposure to low $\mathrm{pH}$, osmotic

Table 1 Lactic acid bacteria used for the selection of GABAproducing strains

\begin{tabular}{|c|c|c|c|c|c|}
\hline \multirow[b]{2}{*}{ Lactobacillus spp. $^{a}$} & \multicolumn{5}{|c|}{ Strains codes } \\
\hline & $J 20$ & $J 22$ & $J 23$ & $J 24$ & $J 25$ \\
\hline & $J 26$ & $J 27$ & $J 28$ & J31 & $J 32$ \\
\hline & $J 34^{*}$ & J37 & $J 38$ & MQ22* & SD22 \\
\hline & SQ31 & LR32 & LR14 & CR24* & SQ33 \\
\hline & LQ24* & MR34 & LM32 & S3 & $\mathrm{SS} 22^{*}$ \\
\hline & SS11 & LS12 & SQ24 & L20 & L8 \\
\hline & LD12* & QR24* & L6 & S37 & LR24 \\
\hline & QR33* & LD24* & LM12 & $\mathrm{LS} 24^{*}$ & SD $11^{*}$ \\
\hline & $\mathrm{SR} 31^{*}$ & QR21* & MQ31* & CD32* & $\mathrm{CD}_{3} 3^{*}$ \\
\hline & S33 & S26 & B26 & $\llcorner 49$ & L21 \\
\hline & L2 Lb C & L2 Lb D & C2 Lb B & $\mathrm{C} 2 \mathrm{Lb} C$ & \\
\hline \multirow[t]{7}{*}{ Streptococcus spp. ${ }^{b}$} & L1 St A & L2 St A & L2 St B & L2 St C & Q2 St A \\
\hline & Q2 St B & Q2 St C & Q2 St D & St26 & St 27 \\
\hline & St 28 & St 32 & St 42 & St 45 & St 50 \\
\hline & St 53 & St 54 & St 35 & St 36 & St 38 \\
\hline & St 39 & St 40 & St 41 & St 44 & Q7 St A \\
\hline & Q7 St A & Q7 St B & Q7 St C & Q7 St D & L7 St A \\
\hline & L7 St D & S7 St D & C7 St B & & \\
\hline \multirow[t]{2}{*}{ Lactococcus spp. $^{c}$} & $L-572^{*}$ & L-599 & Q3 & $L-600$ & $L-598^{*}$ \\
\hline & $L-571^{*}$ & E3 & $\mathrm{C} 1$ & & \\
\hline
\end{tabular}

"GABA-producing strains

a $L A B$ strains isolated from Cocido cheese

b $\mathrm{CAB}$ strains isolated from Fresco cheese

${ }^{c} \mathrm{LAB}$ strains isolated from Chihuahua cheese 
stress, and nutrient deficiency during fermentation. The GAD system converts the glutamic acid molecule in GABA while consuming an intracellular proton (hydrogen ion) (Feehily and Karatzas 2013). The net effect is to reduce the concentration of protons within the cell, decreasing the acidification of the cytoplasm and diminishing any changes in $\mathrm{pH}$ (Le Vo et al. 2012).

Furthermore, Lactobacillus is one of the genera most reported as GABA producers and these strains have been isolated from milk, cheese, fermented milk, and vegetable beverages, and the presence of the GAD has been identified (Siragusa et al. 2007; Di Cagno et al. 2010; Nejati et al. 2013; Franciosi et al. 2015). Even though studies have reported Lactococcus spp. as GABA producers, which have been mainly isolated from dairy products and vegetables, only a few of them have focused on the GAD activity (Lu et al. 2009; Nejati et al. 2013); however, interestingly, 37\% from the Lactococcus spp. strains assessed in the present work showed this enzymatic activity by the qualitative test.

On the other hand, Streptococcus spp. strains have been scarcely reported as GABA producers. In a previous study, the optimum conditions for GAD activity by a specific strain of Streptococcus salivarius were assessed (Yang et al. 2008). In the present study, Streptococcus spp. was found as non-GABA-producing strains. The screening of strains as GABA producers through the use of molecular techniques has been applied to identify the GadA and GadB genes, which encodes the expression of the GAD enzyme in the strains (Sanchart et al. 2017). Nevertheless, it is also reported that the presence of $\mathrm{GAD}^{+}$phenotypes of non-GABA-producing strains related to Streptococcus spp. genus may be usually found (Somkuti et al. 2012). Consequently, the 19 selected strains and the positive control Lactobacillus brevis NBRC 12005 were used to ferment milk and to determine the resulting GABA concentrations.

\section{GABA quantification in $\mathrm{FM}$}

The concentration of GABA was variable among the fermented milk by each strain (Fig. 1). Overall, after $48 \mathrm{~h}$ of fermentation, the FMs with Lactobacillus spp. strains produced $4.2-11.2 \mathrm{mg} / \mathrm{L}$ of GABA and were not significantly different $(p>0.05)$ among them. These concentrations were lower $(p<0.05)$ than that of Lactobacillus brevis NBRC 12005, used as a positive control, which was found to generate $25.7 \pm 2.26 \mathrm{mg} / \mathrm{L}$ of GABA. This prior strain is known to present high GAD activity; therefore, it is widely used in qualitative and quantitative methods to determine potential GABA-producing strains (Sheng-Yuan et al. 2006).

Although the strains assessed produced GABA in lower concentrations, several studies have reported that Lactobacillus spp. are capable of producing different amounts of GABA. Thus, various studies have been carried out in order to evaluate the production of GABA in different substrates, such as culture media, vegetable beverages, meat products, seafood, and mainly dairy products (Di Cagno et al. 2010; Ratanaburee et al. 2013; Shan et al. 2015; Taoka et al. 2019). All these studies report a wide range of GABA production, which naturally depends mainly on the glutamate concentration in the food matrix and the LAB strain used; however, the highest GABA productions have been displayed when the fermentation conditions were modified. For example, yogurt added with Lactobacillus plantarum NDC75017 showed $500 \mathrm{mg} / \mathrm{kg}$ of GABA production, which was related to the activity of the GAD enzyme. However, it

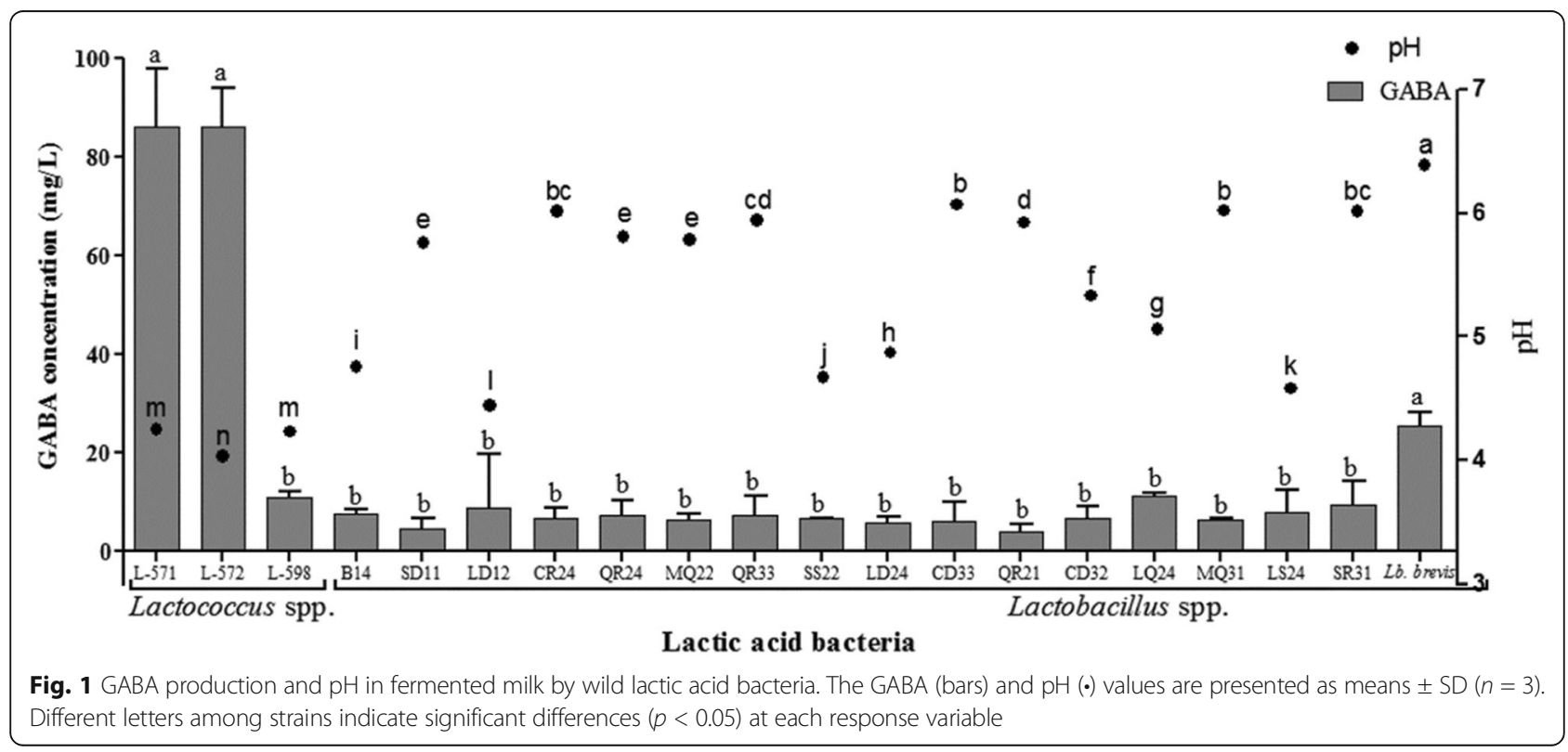


was shown that biomass of the bacterium during fermentation as well as glutamate concentration, positively influenced the GABA production reaching $3145.6 \mathrm{mg} / \mathrm{kg}$ (Shan et al. 2015). In another study, Lactobacillus brevis $877 \mathrm{G}$ produced $1.95 \mathrm{~g} / \mathrm{L}$ of GABA in skim milk. The use of a mixture of Lactobacillus brevis 877G and Lactobacillus sakei 795 (1:1) further enhanced GABA production to $2.32 \mathrm{~g} / \mathrm{L}$ (Seo et al. 2013). It is important to mention that the co-fermentation of different bacteria may increase GABA production due to the competition between the strains in the medium or stress generated in the environment, which may therefore be important conditions to enhance the GABA production.

On the other hand, the FM with Lactococcus L-598 showed a GABA production of $11.0 \pm 1.18 \mathrm{mg} / \mathrm{L}$ and was not significantly different $(p>0.05)$ from those of Lactobacillus spp. assessed in the present work. Furthermore, FM by L-571 and L-572 produced the highest concentration of GABA $(86.0 \pm 11.9$ and $86.2 \pm 7.7 \mathrm{mg} / \mathrm{L}$, respectively) and were not significantly different $(p>0.05)$ between them, but were significantly different $(p<0.05)$ from all the FM. Additionally, it is also important to highlight that these FM produced 3.4-fold GABA than the FM by Lactobacillus brevis.

Notably, the use of Lactococcus spp. strains has become increasingly important in the production and/or fermentation of dairy products for the generation of bioactive compounds (Hagi et al. 2016). Nevertheless, to the best of our knowledge, only a few studies have been focus on the GABA production by Lactococcus spp. strains. In this sense, Nomura et al. (1999) previously reported that fermented skim milk with two Lactococcus lactis strains ATCC 19435 or ATCC 13675 were able to produce GABA equivalent to $21.69 \mathrm{mg} / \mathrm{L}$ and equivalent to $23.30 \mathrm{mg} / \mathrm{L}$, respectively. Moreover, another study reported that Lactococcus lactis NCDO 2118, isolated from frozen peas, produced $20.62 \mathrm{mg} / \mathrm{L}$ of GABA in a chemically defined medium (Mazzoli et al. 2010). Although GABA production of the mentioned studies was similar to our positive control strain, Lactobacillus brevis NBRC $12005(25.7 \mathrm{mg} / \mathrm{L})$, in the present study, our results reveal that our Lactococcus strains presented a high potential to being considered as GABA producers. On the other hand, some studies have been carried out using GABA-producing Lactococcus spp. strains in different substrates, such as culture media and vegetable beverages $(\mathrm{Lu}$ et al. 2009; Laroute et al. 2016); however, dairy products have been the most assessed (Gardner-Fortier et al. 2013; Nejati et al. 2013). In this sense, Lactococcus spp. strains were evaluated to produce GABA under different fermentation conditions, and it was revealed that they presented a high potential as GABA producers if suitable conditions are established, such as the adjustment of the substrate concentration, temperature, and $\mathrm{pH}$ ( $\mathrm{Lu}$ et al. 2009).
The acidifying capacity of Lactococcus spp. strains were also determined in our study, and we found diverse capacities, ranging 4-6 of $\mathrm{pH}$ (Fig. 1), suggesting a strain-dependent behavior. Overall, the FM with the Lactococcus spp. were significantly lower $(p<0.05)$ than those of Lactobacillus spp., and specifically strains L-571 and L-571 showed the lowest $\mathrm{pH}$, suggesting that the acidifying capacity may be related with the capacity to produce GABA. In fact, it has been reported that the GAD enzyme optimally acts on the bioconversion of glutamic acid to GABA at a pH of 4.4 (Huang et al. 2016), which may explain the high production of strains L-571 and L-571. Nevertheless, L-598, LD12 and LS24 presented $\mathrm{pH}$ values lower than 4.5 , presenting significantly lower $(p<0.05)$ concentrations of GABA compared to the FM with L-571 or L-572 strains. In these particular cases, the low GABA production may be associated with other factors, such as their optimum growing conditions (Minervini et al. 2009) or the expression of the GAD enzyme of the strains (Li et al. 2013). In addition, some authors have suggested that in some strains, there may be deficiencies in the transport system of glutamate-GABA towards the inside and outside of the cell (Feehily and Karatzas 2013) or that the assimilated glutamate could be used in other metabolic pathways, which would limit the production of GABA (Fernandez and Zuniga 2006).

In another study, the acidifying potential of Lactococcus spp. strains was analyzed in order to evaluate how acidity influences the biosynthesis of GABA in FM enriched with glutamate. The results showed that $70 \mathrm{mg} / \mathrm{L}$ of GABA were produced in FM (Gardner-Fortier et al. 2013). Different LAB isolated from Japanese fermented products (sea products) were assessed for their potential to produce GABA at different $\mathrm{pH}$ ranges. The highest GABA production was found at a pH between 5 and 6 $(8000 \mathrm{mg} / \mathrm{kg})$, decreasing the concentration of GABA at lower $\mathrm{pH}(<1000 \mathrm{mg} / \mathrm{kg})$ and the level of production was specific to each strain (Barla et al. 2016).

The current research trend of assessing GABA production in food matrices is focused on the standardization and/or optimization of fermentation processes in order to increase GABA concentrations (Tajabadi et al. 2015). In this sense, our results showed that $L$. lactis were promising; however, since it is reported that $100-120 \mathrm{mg} / \mathrm{L}$ of GABA is required to exert beneficial effects (Inoue et al. 2003), strategies to enhance the GABA yield should be applied in an attempt to achieve this target. According to the results of the present study, the Lactococcus spp. strains L-571 and L-572 presented the greatest potential for producing GABA; hence, they were selected to evaluate whether the modification of fermentation conditions or the co-fermentation of these strains would increase the GABA production. 
Modification of fermentation conditions to increase GABA synthesis in FM

It has been widely reported that GABA production by LAB is affected by culture conditions and the medium composition ( $\mathrm{Li}$ and Cao 2010). Therefore, in the present study, the fermentation conditions and medium compositions were modified to enhance GABA production. The selected working strains were NRRL B-50571 (L-571) and NRRL B-50572 (L-572).

The results of the fermentation conditions (inoculum concentration and incubation temperature) are depicted in Fig. 2. L-571 showed the highest GABA production with a concentration of inoculum of $10^{7} \mathrm{CFU} / \mathrm{mL}$ (30 ${ }^{\circ} \mathrm{C}$ ) and $10^{9} \mathrm{CFU} / \mathrm{mL}\left(37{ }^{\circ} \mathrm{C}\right)$ with $915.6 \pm 133.2$ and $897.7 \pm 6.3 \mathrm{mg} / \mathrm{L}$, respectively, and were not significantly $(p>0.05)$ between them. However, FM with an inoculum of $10^{9} \mathrm{CFU} / \mathrm{mL}$ incubated at $37^{\circ} \mathrm{C}$ during $48 \mathrm{~h}$ was selected for further analysis. Likewise, the same fermentation conditions were selected for L-572, since they allowed to significantly $(p<0.05)$ generate the highest GABA production $(138.2 \pm 24.2 \mathrm{mg} / \mathrm{L})$.

Overall, according to the temperature and inoculum concentrations assessed, $37{ }^{\circ} \mathrm{C}$ and $10^{9} \mathrm{CFU} / \mathrm{mL}$ were the conditions that displayed the best GABA production, since they allowed to enhance 10-fold and 1.6-fold of GABA production for L-571 and L-572, respectively, in milk enriched with $1 \%$ of glutamate. Therefore, these conditions were selected for each FM. It was previously reported that the optimal temperature for GABA production with $\mathrm{LAB}$ ranges $30-50{ }^{\circ} \mathrm{C}$ and was concluded that it is strain-dependent ( $\mathrm{Li}$ and Cao 2010). In fact, the optimum fermentation conditions for some LAB may not match the optimum GABA synthesis conditions (Dhakal et al. 2012), since it is widely reported that
Lactococcus lactis spp. optimally grows at $30-32{ }^{\circ} \mathrm{C}$ (Chen et al. 2015); however, $37{ }^{\circ} \mathrm{C}$ allowed the highest GABA production.

Therefore, controlling the fermentation process may be used to optimize the GABA production. In this sense, Yang et al. (2008) carried out a controlled experiment in two stages testing different $\mathrm{pH}$ and temperature conditions to achieve optimum GABA production. The GAD activity for Streptococcus salivarius subsp. thermophilus Y2 was evaluated and they reported that after adjusting the optimal temperature at $40{ }^{\circ} \mathrm{C}$ and $\mathrm{pH}$ at 4.5 , the GAD activity allowed an increase in GABA production up to 1.76-fold (Yang et al. 2008).

To the best of our knowledge, there are only a few reports on the effect of different inoculum concentrations in terms of poblational density for optimizing GABA production in FM. However, a study carried out an optimization analysis of GABA production in a chickpea-based beverage using Lactobacillus plantarum M-6 and the inoculum (on the basis of $\left.10^{7} \mathrm{CFU} / \mathrm{mL}\right)$ was added in different concentrations $(3 \%, 5 \%$, and $7 \%$ ). They concluded that inoculation at $7 \%$ resulted in the highest GABA production, because a higher concentration of inoculum may produce more cellular biomass, possibly allowing greater conversion of glutamate to GABA ( $\mathrm{Li}$ et al. 2016). Similarly, in the present study, results indicated that the more cellular biomass, the more GABA production was enhanced. Lastly, the selected fermentation conditions for each FM were used for further analyses, in order to assess the effect of different glutamate concentrations on the GABA production. In addition, a co-fermentation of both strains (L-571/L-572, 1:1) was also assessed.

The results of the effect of different glutamate concentrations on the GABA production are shown in Fig. 3. It was observed that by enriching glutamate concentration

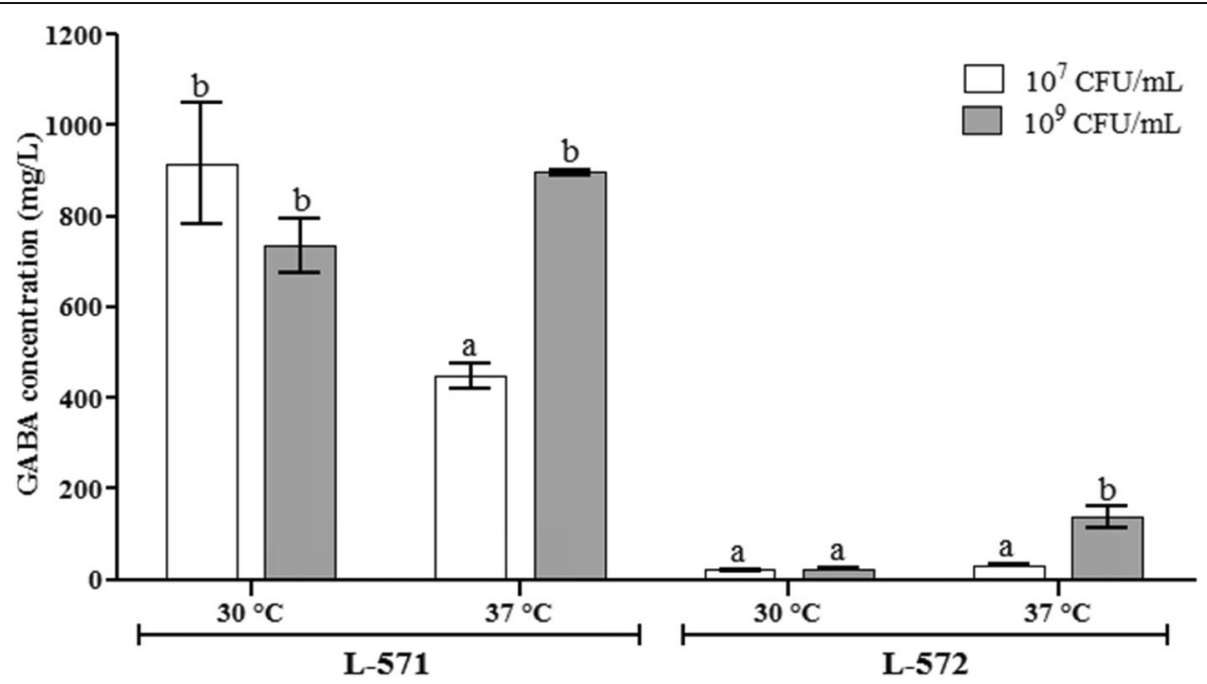

Fig. 2 GABA concentrations in fermented milk using L-571 and L-572 strains at different fermentation conditions. The results show means \pm SD $(n=3)$. Different letters, among fermentation condition for each strain, indicate significant differences $(p<0.05)$ 


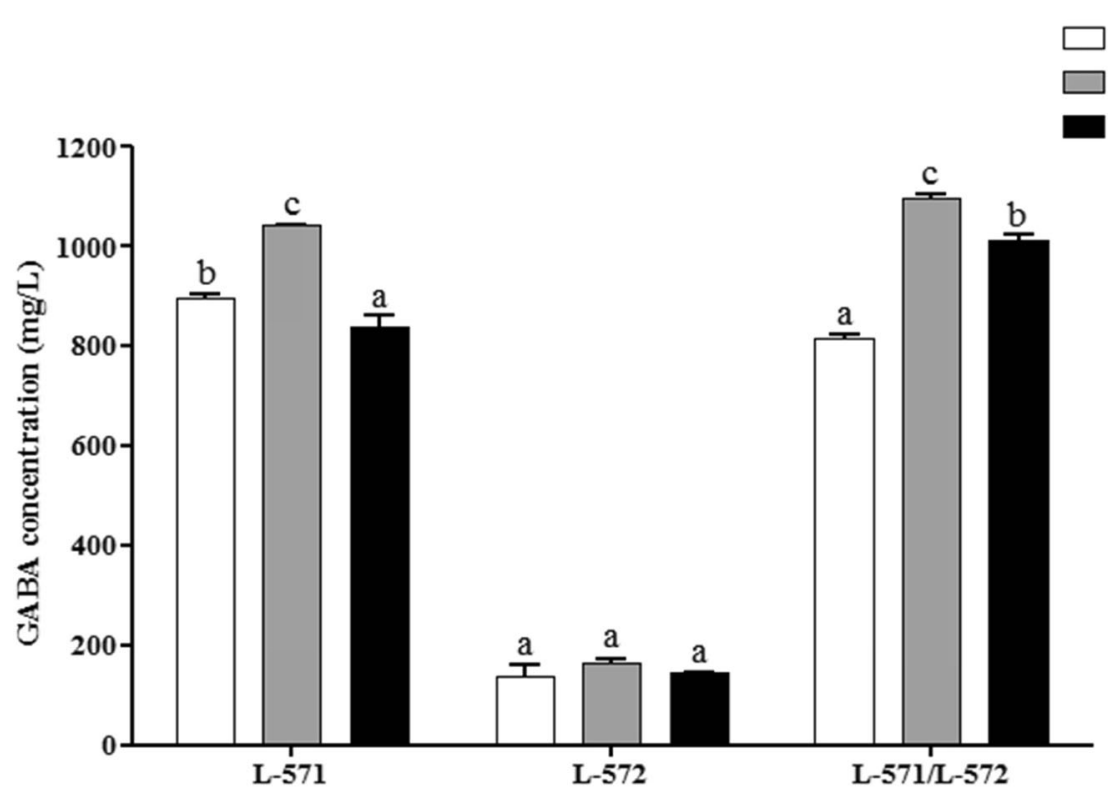

Fig. 3 GABA production in fermented milk using L-571, L-572 and L-571/L-572 strains at different glutamate concentrations. The results show means \pm SD ( $n=3)$. Different letters, among glutamate concentrations for each FM (L-571, L-572 or L-571/L-572), indicate significant differences $(p<0.05)$

in milk from 1 to $3 \mathrm{~g} / \mathrm{L}$, FM with L-571 and L-571/L-572 significantly $(\mathrm{p}<0.05)$ enhanced the GABA production up to $16 \%$ and $34.5 \%$ more, respectively. Nevertheless, when milk was enriched up to $5 \mathrm{~g} / \mathrm{L}$ of glutamate, GABA production significantly decreased in both FMs. On the other hand, FM with L-572 did not show significant differences $(p>0.05)$ among the glutamate concentrations.

Several studies have reported that enriching milk with glutamate positively influence GABA production (Dhakal et al. 2012). In this sense, the effects of fermentation conditions, including glutamate enrichment, were assessed in an attempt to enhance the GABA yield by a specific strain of Lactococcus lactis. They concluded that glutamate was the most significant factor influencing GABA yield and the optimal condition was at $15 \mathrm{~g} / \mathrm{L}$ of enrichment achieving 7.2 g/L of GABA (Lu et al. 2009). These findings clearly reveal that a high GABA yield may be displayed by Lactococcus spp.; however, diverse results have been reported by different strains of lactic acid bacteria cultured in a wide variety of matrices and fermentation conditions

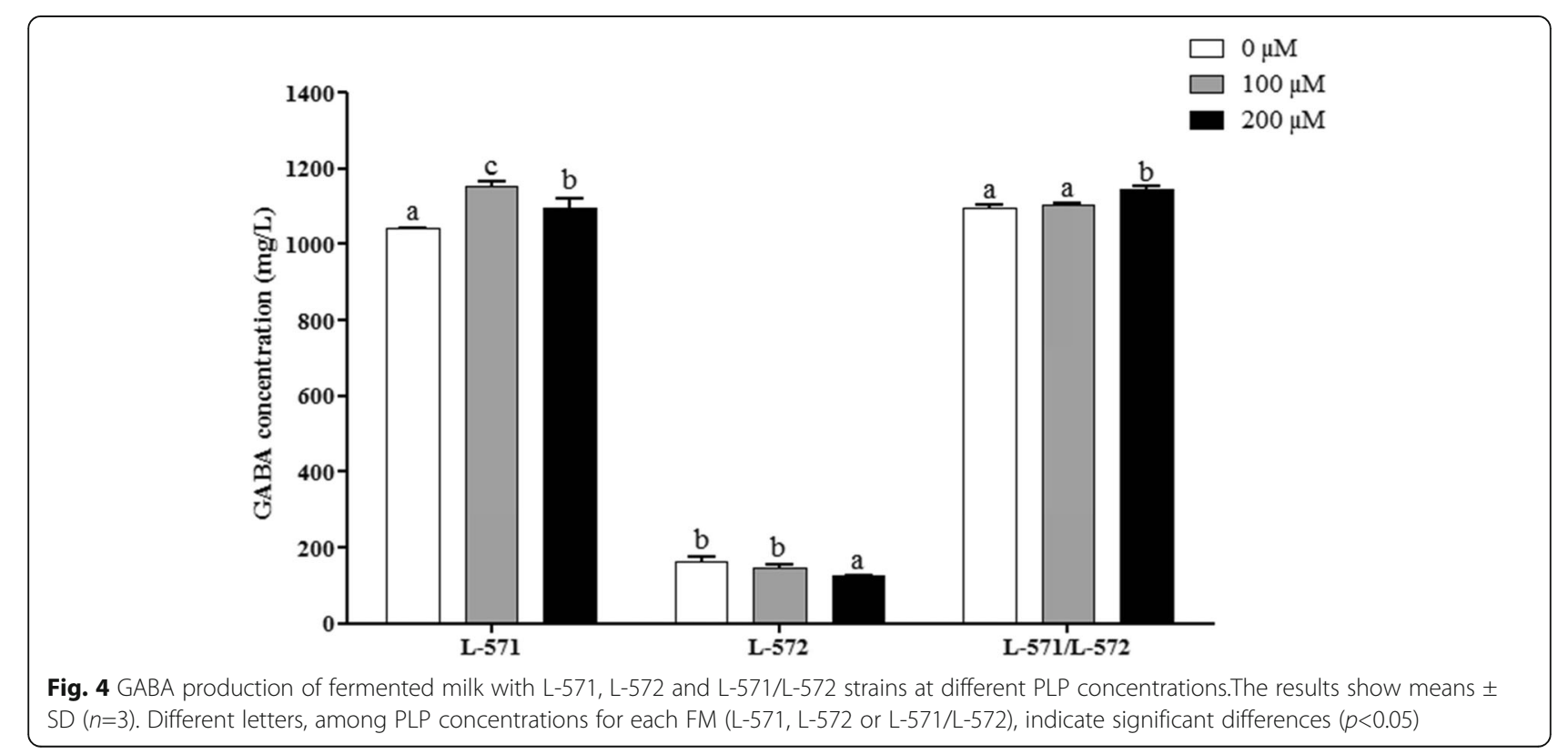


(Dhakal et al. 2012), which denotes that this activity is strain-dependent. Specifically, in fermented milk, the GABA concentrations obtained in the present study were superior to those reported by other authors who encountered a GABA production of $258.7 \mathrm{mg} / \mathrm{L}$ by Lactococcus lactis subsp. cremoris and $629 \mathrm{mg} / \mathrm{L}$ by Lactobacillus plantarum NTU 102 following the addition of $10 \mathrm{~g} / \mathrm{L}$ of glutamate (Tung et al. 2011).

Since the enrichment of milk with $3 \mathrm{mg} / \mathrm{L}$ of glutamate showed the best GABA production in the present study, this condition was selected for further analyses with different PLP concentrations in order to enhance the GABA yield. PLP is an enzymatic cofactor that bacteria use to improve the efficiency or activity of the GAD enzyme, thereby favoring the production of GABA (Li et al. 2016). Although it has been previously reported that PLP may be present in milk in low concentrations $(3 \mu \mathrm{M})$ (Schimdt et al. 2017), in the present study, the PLP concentrations of 100 and $200 \mu \mathrm{M}$ as an additive in milk were assessed. The results, depicted in Fig. 4, showed that the enrichment with $100 \mu \mathrm{M}$ of PLP significantly $(p<0.05)$ enhanced the GABA yield in FM with L-571, increasing up to $10.7 \%$. However, when milk was enriched with $200 \mu \mathrm{M}$ of PLP, L-571 significantly $(p<0.05)$ decreased by $4.9 \%$ its yield. In contrast, L-571/L-572 significantly $(p<0.05)$ improved its production with $200 \mu \mathrm{M}$, achieving an increase of $4.5 \%$. Conversely, although FM with the singular culture of L-572 did not show improvement when $100 \mu \mathrm{M}$ of PLP was added to the milk, GABA yield was significantly ( $p<$ 0.05 ) decreased $23.9 \%$ when $200 \mu \mathrm{M}$ of PLP was added.

These results revealed that to enrich milk with 100 $\mu \mathrm{M}$ of PLP before the fermentation process, it may
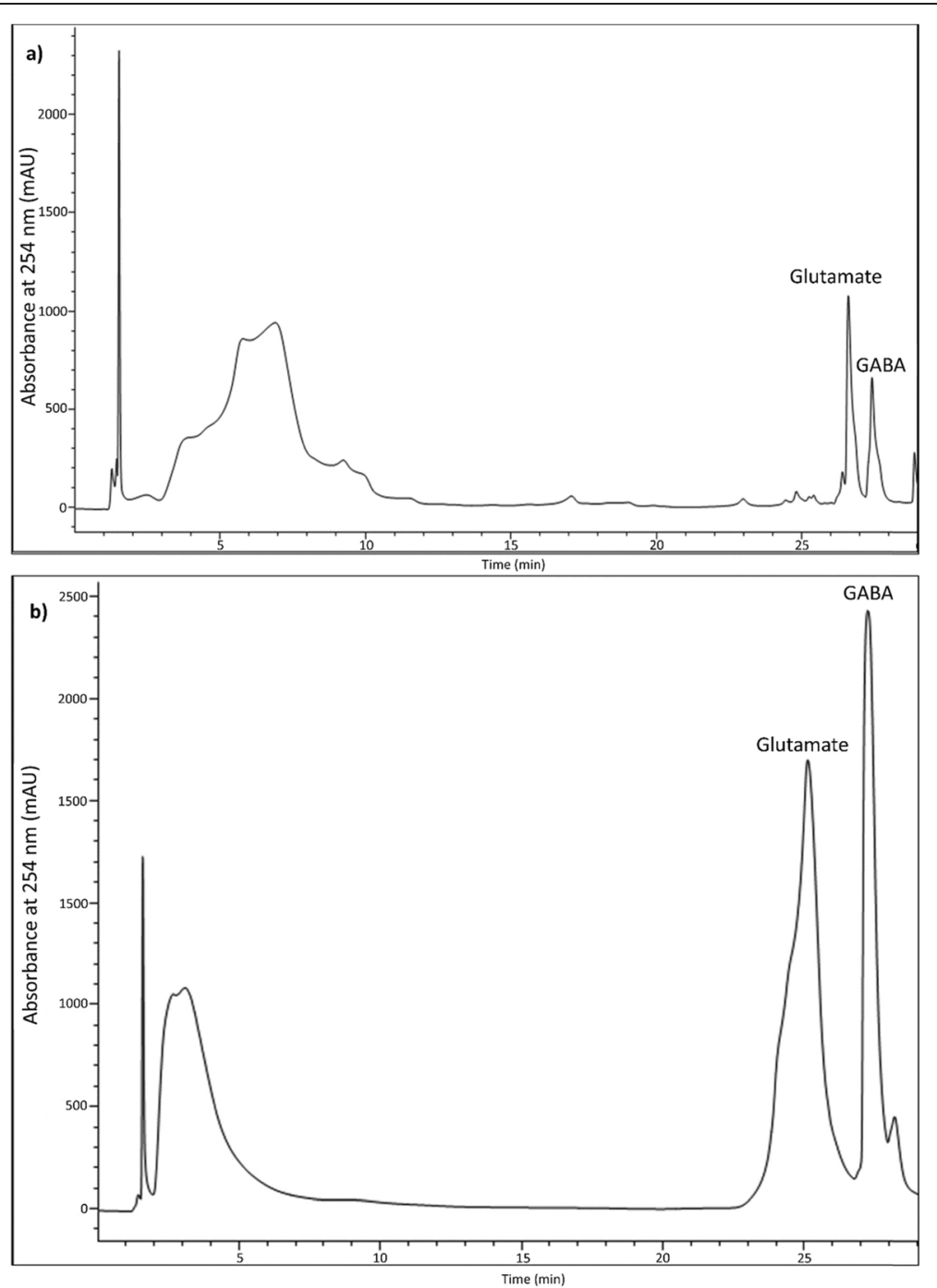

Fig. 5 Chromatographic profile of GABA production in fermented milk with L. lactis L-571 under unmodified $\left(30^{\circ} \mathrm{C}\right.$ of incubation, $10^{7} \mathrm{CFU} / \mathrm{mL}$ of inoculum, $0 \mathrm{~g} / \mathrm{L}$ of glutamate, and $0 \mu \mathrm{M}$ of PLP) (a) and modified $\left(37^{\circ} \mathrm{C}\right.$ of incubation, $10^{9} \mathrm{CFU} / \mathrm{mL}$ of inoculum, $3 \mathrm{~g} / \mathrm{L}$ of glutamate, and $100 \mu \mathrm{M}$ of PLP) (b) fermentation conditions 
maintain or even increase the GABA production by L571, L-572, or L-571/L-572. However, to increase more than $100 \mu \mathrm{M}$ may lead to improve the GABA yield, as it was shown for L-571/L-572 or be decreased as in FM with L-572. Similar studies with Lactobacillus brevis and Lactobacillus plantarum were carried out by assessing four different concentrations of PLP, and it was found that the optimum concentration was $200 \mu \mathrm{M}$ (Gomaa 2015). Therefore, PLP may be considered as an additive in order to enhance the GABA yield.

Notably, in the present study, we managed to increase the GABA present in FM, which is associated with beneficial health effects such as the antihypertensive effect (Inoue et al. 2003; Hayakawa et al. 2004) by more than 20-fold using the strains L-571 and L-571/L-572 compared to the GABA concentrations previously reported (Beltrán-Barrientos et al. 2018a). Nevertheless, it is interesting to note that different GABA production capacities may be exerted by Lactococcus spp. as it was shown in the present study by L-571 and L572. The lower capacity of the last strain may be due to the oversaturation of the glutamate in medium, since it increases the osmotic stress or deficiencies in the transport of GABA or glutamate to outside or inside the cellular cytoplasm of the strain (Wang et al. 2018). Conversely, when two or more strains coexist in the same medium, there is greater competition for nutrients and greater osmotic stress, which may positively influence the fermentation processes for GABA synthesis (Xu et al. 2017). In this case, after selecting the suitable conditions, our study disclosed that the cofermentatation L-571/L-572 (1147.4 $\pm 6.7 \mathrm{mg} / \mathrm{L})$ did not significantly $(p>0.05)$ enhance the GABA production displayed by the singular culture of L-571 $(1153.1 \pm 13.5 \mathrm{mg} / \mathrm{L})$. Actually, the FM of the strain L-571 achieved to increase the GABA yield up to 13.4-fold compared when conditions were not adjusted (Fig. 5). Therefore, Lactococcus lactis L-571 seems to be the strain predominant in the production of GABA and further studies may determine their optimum yield taken into account these specific considerations.

\section{Conclusions}

In this study, we revealed that specific wild GABA-producing strains, isolated from artisanal Mexican cheeses, may exert an enhancement of GABA production in FM by adjusting their fermentation conditions. Lactococcus lactis strains L571 and L-572 showed the highest production without modified fermentation conditions. However, after assessing the fermentation conditions, FM with L-571 showed the highest GABA production and its yield was significantly enhanced at $37^{\circ} \mathrm{C}$ of incubation, $10^{9} \mathrm{CFU} / \mathrm{mL}$ of inoculum, $3 \mathrm{~g} / \mathrm{L}$ of glutamate, and $100 \mu \mathrm{M}$ of PLP. Thus, further studies are needed to establish the optimum conditions for producing GABA by this strain and in vivo studies may reveal its potential use as GABA-producing culture for fermented functional foods. Our results allowed us to highlight the importance of wild
LAB strains isolated from natural sources, such as artisanal Mexican cheeses, in order to generate new alternatives and opportunities in the development of foods containing GABA with potentially beneficial effects.

\section{Acknowledgements}

The authors would also like to thank the Mexican Council of Science and Technology (CONACyT; Mexico City, Mexico) for the graduate scholarship provided to Santos-Espinosa Alejandro.

\section{Authors' contributions}

Conceptualization: AFGC. Experimental design: AFGC, BVC. Laboratory analysis: ASE. Supervision: AFGC, MMM, AHM, SGSA, GAGA. Data analysis and interpretation: ASE, RRD, LMBB. Manuscript drafting: ASE, LMBB. Manuscript review \& editing: All authors. Manuscript approval: All authors read and approved the final manuscript.

\section{Funding}

This study was supported by the Mexican Council of Science and Technology (CONACyT), Research Project Ciencia Básica No. 240338.

\section{Ethics approval and consent to participate}

N/A

\section{Consent for publication}

N/A

\section{Competing interests}

The authors declare that they have no competing interest.

\section{Author details}

${ }^{1}$ Laboratorio de Química y Biotecnología de Productos Lácteos, Centro de Investigación en Alimentación y Desarrollo, A. C. (CIAD, A.C.), Carretera Gustavo Enrique Astiazarán Rosas \# 46, Colonia La Victoria, 83304 Hermosillo, Sonora, Mexico. ${ }^{2}$ Laboratorio de Antioxidantes y Alimentos Funcionales, Centro de Investigación en Alimentación y Desarrollo, A. C. (CIAD, A.C.), Carretera Gustavo Enrique Astiazarán Rosas \# 46, Colonia La Victoria, 83304 Hermosillo, Sonora, Mexico. ${ }^{3}$ Tecnológico Nacional de México/Instituto Tecnológico de Tepic, Av. Instituto Tecnológico \#2595, Colonia Lagos del Country, 63175 Tepic, Nayarit, Mexico.

Received: 7 September 2019 Accepted: 29 January 2020

Published online: 04 March 2020

\section{References}

Barla F, Koyanagi T, Tokuda N, Matsui H, Katayama T, Kumagai H, Michihata T, Sasaki T, Tsuji A, Enomoto T (2016) The $\gamma$-aminobutyric acid-producing ability under low pH conditions of lactic acid bacteria isolated from traditional fermented foods of Ishikawa Prefecture, Japan, with a strong ability to produce ACE-inhibitory peptides. Biotechnol Rep (Amst) 10:105-110

Beltrán-Barrientos LM, Estrada-Montoya C, Reyes-Díaz R, Hernández-Mendoza A, González-Córdova AF, Vallejo-Córdoba B (2018a) Does gamma-aminobutyric acid have a potential role on the antihypertensive effect of fermented milk with Lactococcus lactis NRRL B-50571? J Funct Foods 48:297-301

Beltrán-Barrientos LM, Hernández-Mendoza A, González-Córdova AF, AstiazaranGarcía H, Esparza-Romero J, Vallejo-Cordoba B (2018b) Mechanistic pathways underlying the antihypertensive effect of fermented milk with Lactococcus lactis NRRL B-50571 in spontaneously hypertensive rats. Nutrients 10(3)

Chen J, Shen J, Ingvar Hellgren L, Ruhdal Jensen P, Solem C (2015) Adaptation of Lactococcus lactis to high growth temperature leads to a dramatic increase in acidification rate. Sci Rep 5:14199

Cotter PD, Gahan CG, Hill C (2001) A glutamate decarboxylase system protects Listeria monocytogenes in gastric fluid. Mol Microbiol 40(2):465-475

Dhakal R, Bajpai VK, Baek KH (2012) Production of gaba ( - Aminobutyric acid) by microorganisms: a review. Braz J Microbiol 43(4):1230-1241

Di Cagno R, Mazzacane S, Rizzello CG, De Angelis M, Giuliani G, Meloni M, De Servi B, Gobbetti M (2010) Synthesis ofy-aminobutyric acid (GABA) by Lactobacillus plantarum DSM19463: functional grape must beverage and dermatological applications. Appl Microbiol Biotechnol 86(2):731-741 
Diana M, Quílez J, Rafecas M (2014a) Gamma-aminobutyric acid as a bioactive compound in foods: a review. J Funct Foods 10:407-420

Diana M, Rafecas M, Arco C, Quílez J (2014b) Free amino acid profile of Spanish artisanal cheeses: importance of gamma-aminobutyric acid (GABA) and ornithine content. J Food Comp Anal 35(2):94-100

Feehily C, Karatzas KAG (2013) Role of glutamate metabolism in bacterial responses towards acid and other stresses. J Appl Microbiol 114(1):11-24

Fernandez M, Zuniga M (2006) Amino acid catabolic pathways of lactic acid bacteria. Crit Rev Microbiol 32(3):155-183

Franciosi E, Carafa I, Nardin T, Schiavon S, Poznanski E, Cavazza A, Larcher R, Tuohy KM (2015) Biodiversity and $\gamma$-aminobutyric acid production by lactic acid bacteria isolated from traditional alpine raw cow's milk cheeses. BioMed Res Int https://doi.org/10.1155/2015/625740

Gardner-Fortier C, St-Gelais D, Champagne CP, Vuillemard JC (2013) Determination of optimal conditions for $\gamma$-aminobutyric acid production by Lactococcus lactis ssp. lactis. Int Dairy J 32(2):136-143

Gomaa EZ (2015) Enhancement of $\gamma$-amminobutyric acid production by coculturing of two lactobacilli strains. Asian J Biotechnol 7(3):108-118

Gonzalez-Gonzalez CR, Machado J, Correia S, McCartney AL, Elmore JE, Jauregi P (2019) Highly proteolytic bacteria from semi-ripened Chiapas cheese elicit angiotensin-I converting enzyme inhibition and antioxidant activity. LWT Food Sci Technol 111:449-456

Gutierrez N (2008) Capacidad de Lactococcus lactis de biosintetizaar acetoglutarato asociado con su potencial de producir aroma. Dissertation. Centro de Investigación en Alimentación y Desarrollo, A.C

Hagi T, Kobayashi M, Nomura M (2016) Metabolome analysis of milk fermented by Y-aminobutyric acid-producing Lactococcus lactis. J Dairy Sci 99(2):994-1001

Hayakawa K, Kimura M, Kasaha K, Matsumoto K, Sansawa H, Yamori Y (2004) Effect of a gamma-aminobutyric acid-enriched dairy product on the blood pressure of spontaneously hypertensive and normotensive Wistar-Kyoto rats. Br J Nutr 92:411-417

Heredia P (2011) Caracterización del proceso de producción del queso Cocido artesanal y de las principales bacterias ácido lácticas generadoras del aroma. Dissertation. Centro de Investigación en Alimentación y Desarrollo, A.C

Hintze J (2006) NCSS, PASS, and GESS. NCSS, Kaysville

Huang Y, Su L, Wu J (2016) Pyridoxine supplementation improves the activity of recombinant glutamate decarboxylase and the enzymatic production of gamaaminobutyric acid. PLoS One. https://doi.org/10.1371/journal.pone.0157466

Inoue K, Shirai T, Ochiai H, Kasao M, Hayakawa K, Kimura M, Sansawa H (2003) Blood-pressure-lowering effect of a novel fermented milk containing gammaaminobutyric acid (GABA) in mild hypertensives. Eur J Clin Nutr 57(3):490-495

Jeng KC, Chen CS, Fang YP, Hou RCW, Chen YS (2007) Effect of microbial fermentation on content of statin, GABA, and polyphenols in Pu-Erh tea. J Agric Food Chem 55(21):8787-8792

Komatsuzaki N, Nakamura T, Kimura T, Shima J (2008) Characterization of glutamate decarboxylase from a high gamma-aminobutyric acid (GABA)producer, Lactobacillus paracasei. Biosci Biotechnol Biochem 72(2):278-285

Komatsuzaki N, Shima J, Kawamoto S, Momose H, Kimura T (2005) Production of gamma-aminobutyric acid (GABA) by Lactobacillus paracasei isolated from traditional fermented foods. Food Microbiol 22(6):497-504

Lacroix N, St-Gelais D, Champagne CP, Vuillemard JC (2013) Gammaaminobutyric acid-producing abilities of lactococcal strains isolated from oldstyle cheese starters. Dairy Sci Technol 93(3):315-327

Laroute $V$, Yasaro Y, Narin W, Mazzoli R, Pessione E, Cocaign-Bousquet M, Loubière P (2016) GABA production in Lactococcus lactis is enhanced by arginine and coaddition of malate. Front Microbiol. https://doi.org/10.3389/fmicb.2016.01050

Le Vo TD, Kim TW, Hong SH (2012) Effects of glutamate decarboxylase and gamma-aminobutyric acid (GABA) transporter on the bioconversion of GABA in engineered Escherichia coli. Bioprocess Biosystems Eng 35(4):645-650

Li H, Cao Y (2010) Lactic acid bacterial cell factories for gamma-aminobutyric acid. Amino Acids 39(5):1107-1116

Li H, Li W, Liu X, Cao Y (2013) gadA gene locus in Lactobacillus brevis NCL912 and its expression during fed-batch fermentation. FEMS Microbiol Lett 349(2):108-116

Li W, Wei M, Wu J, Rui X, Dong M (2016) Novel fermented chickpea milk with enhanced level of $\gamma$-aminobutyric acid and neuroprotective effect on PC12 cells. PeerJ. https://doi.org/10.7717/peerj.2292

Lu X, Chen Z, Gu Z, Han Y (2008) Isolation of Y-aminobutyric acid-producing bacteria and optimization of fermentative medium. Biochem Eng J 41(1): $48-52$

Lu XX, Xie CY, Gu ZX (2009) Optimisation of fermentative parameters for GABA enrichment by Lactococcus lactis. Czech J Food Sci 27(6):433-442
Mazzoli R, Pessione E, Dufour M, Laroute V, Giuffrida MG, Giunta C, CocaignBousquet M, Loubiere P (2010) Glutamate-induced metabolic changes in Lactococcus lactis NCDO 2118 during GABA production: combined transcriptomic and proteomic analysis. Amino Acids 30:727-737

Minervini F, Bilancia MT, Siragusa S, Gobbetti M, Caponio F (2009) Fermented goats' milk produced with selected multiple starters as a potentially functional food. Food Microbiol 26(6):559-564

Nejati F, Rizzello CG, Di Cagno R, Sheikh-Zeinoddin M, Diviccaro A, Minervini F, Gobbetti M (2013) Manufacture of a functional fermented milk enriched of Angiotensin-I Converting Enzyme (ACE)-inhibitory peptides and $\gamma$-amino butyric acid (GABA). LWT Food Sci Technol 51(1):183-189

Nomura M, Kimoto H, Someya Y, Suzuki I (1999) Novel characteristic for distinguishing Lactococcus lactis subsp. lactis from subsp. cremoris. Int J Syst Bacteriol 49:163-166

Ratanaburee A, Kantachote D, Charernjiratrakul W, Sukhoom A (2013) Selection of $\gamma$-aminobutyric acid-producing lactic acid bacteria and their potential as probiotics for use as starter cultures in Thai fermented sausages (Nham). J Food Sci Technol 48(7):1371-1382

Rodríguez-Figueroa JC, Reyes-Díaz R, González-Córdova AF, Troncoso-Rojas R, Vargas-Arispuro I, Vallejo-Cordoba B (2010) Angiotensin-converting enzyme inhibitory activity of milk fermented by wild and industrial Lactococcus lactis strains. J Dairy Sci 93(11):5032-5038

Sanchart C, Rattanaporn O, Haltrich D, Phukpattaranont P, Maneerat S (2017) Lactobacillus futsaii CS3, a new GABA-producing strain isolated from Thai fermented shrimp (Kung-Som). Indian J Microbiol 57(2):211-217

Schimdt A, Scheirner MG, Mayer HK (2017) Rapid determination of the various native forms of vitamin B6 and B2 in cow's milk using ultra-high performance liquid chromatography. J Chromatography A 1500:89-95

Seo MJ, Nam YD, Park SL, Lee SY, Yi SH, Lim SI (2013) Y-aminobutyric acid production in skim milk co-fermented with Lactobacillus brevis $877 \mathrm{G}$ and Lactobacillus sakei 795. Food Sci Biotechnol 22(3):751-755

Serrano JM (2012) Caracterización de bacterias ácido lácticas aisladas de queso Fresco artesanal de Mazatán Sonora. Dissertation. Universidad Autónoma de Chapingo

Shan Y, Man CX, Han X, Li L, Guo Y, Deng Y, Li T, Zhang LW, Jiang YJ (2015) Evaluation of improved $\gamma$-aminobutyric acid production in yogurt using Lactobacillus plantarum NDC75017. J Dairy Sci 98(4):2138-2149

Sheng-Yuan Y, Zhao-Xin LU, Feng-Xia LÜ, Xiao-Mei BIE, Li-Jun SUN, XiaoXiong $Z$ (2006) A simple method for rapid screening of bacteria with glutamate decarboxylase activities. J Rapid Methods Automation Microbiol 14(3):291-298

Shi F, Li Y (2011) Synthesis of gamma-aminobutyric acid by expressing Lactobacillus brevis-derived glutamate decarboxylase in the Corynebacterium glutamicum strain ATCC 13032. Biotechnol Lett 33(12):2469-2474

Siragusa S, De Angelis M, Di Cagno R, Rizzello CG, Coda R, Gobbetti M (2007) Synthesis of $\gamma$-aminobutyric acid by lactic acid bacteria isolated from a variety of Italian cheeses. Appl Environ Microbiol 73(22):7283-7290

Somkuti GA, Renye JA Jr, Steinberg DH (2012) Molecular analysis of the glutamate decarboxylase locus in Streptococcus thermophilus ST110. J Indus Microbiol Biotechnol 39(7):957-963

Song HY, Yu RC (2017) Optimization of culture conditions for gammaaminobutyric acid production in fermented adzuki bean milk. J Food Drug Anal 26(1):74-81

Tajabadi N, Ebrahimpour A, Baradaran A, Rahim RA, Mahyudin NA, Manap MY, Bakar FA, Saari N (2015) Optimization of gamma-aminobutyric acid production by Lactobacillus plantarum Taj-Apis362 from honeybees. Molecules 20(4):6654-6669

Taoka Y, Nakamura M, Nagai S, Nagasaka N, Tanaka R, Uchida K (2019) Production of anserine-rich fish sauce from giant masu salmon, oncorhynchus masou masou and $\gamma$-aminobutyric acid (GABA)-enrichment by Lactobacillus plantarum train N10. Fermentation 5(2):45

Tung YT, Lee BH, Liu CF, Pan TM (2011) Optimization of culture condition for ACEl and GABA production by lactic acid bacteria. J Food Sci 76(9):M585M591

Wang C, Cui Y, Qu X (2018) Mechanisms and improvement of acid resistance in lactic acid bacteria. Arch Microbiol 200(2):195-201

Wu Q, Shah NP (2016) Gas release-based prescreening combined with reversedphase HPLC quantitation for efficient selection of high- $\gamma$-aminobutyric acid (GABA)-producing lactic acid bacteria. J Dairy Sci 98(2):790-797

Xu N, Wei L, Liu J (2017) Biotechnological advances and perspectives of gammaaminobutyric acid production. World J Microbiol Biotechnol 33(3):64 
Yang SY, Lu FX, Lu ZX, Bie XM, Jiao Y, Sun L, Yu B (2008) Production of gammaaminobutyric acid by Streptococcus salivarius subsp. thermophilus Y2 under submerged fermentation. Amino Acids 34(3):473-478

Yu K, Hu S, Huang J, Mei LH (2011) A high-throughput colorimetric assay to measure the activity of glutamate decarboxylase. Enzyme Microb Technol 49(3):272-276

\section{Publisher's Note}

Springer Nature remains neutral with regard to jurisdictional claims in published maps and institutional affiliations.

Ready to submit your research? Choose BMC and benefit from:

- fast, convenient online submission

- thorough peer review by experienced researchers in your field

- rapid publication on acceptance

- support for research data, including large and complex data types

- gold Open Access which fosters wider collaboration and increased citations

- maximum visibility for your research: over $100 \mathrm{M}$ website views per year

At BMC, research is always in progress.

Learn more biomedcentral.com/submissions 